Check for updates

Cite this: RSC Adv., 2017, 7, 52812

Received 14th August 2017

Accepted 31st October 2017

DOI: 10.1039/c7ra08966j

rsc.li/rsc-advances

\section{Fabrication of N1-butyl substituted 4,5-dimethyl- imidazole based crosslinked anion exchange membranes for fuel cells}

\author{
Jinkai Hao, (D) ${ }^{\text {ab }}$ Xueqiang Gao, ${ }^{\text {ab }}$ Yongyi Jiang, ${ }^{\text {ab }}$ Feng Xie, $^{\text {ab }}$ Zhigang Shao (D)*a \\ and Baolian $\mathrm{Yi}^{\mathrm{a}}$
}

Novel N1, C4, C5-substituted imidazolium-based crosslinked anion exchange membranes (AEMs) are prepared by the incorporation of polybenzimidazole (PBI) into the poly(vinylbenzyl chloride) (PVBC) matrix. 1-Butyl-4,5dimethyl-imidazole (BDIm) with methyl substituents at C4, C5 and long side alkyl substituents at N1 is firstly synthesized to enhance the stability of AEMs by steric hindrance and hyperconjugative effects and characterized by ${ }^{1} \mathrm{H}$ NMR. The effects of crosslinking density of AEMs on the hydroxide conductivity, swelling ratio, thermal stability, oxidative and alkaline stability are evaluated in detail for fuel cell applications. The results reveal that the crosslinking structure between PVBC and PBI plays a vital role in achieving both good mechanical properties and low swelling ratio. Notably, the AEM containing $66.7 \%$ PVBC has the highest ionic conductivity of $16.1 \mathrm{mS} \mathrm{cm}^{-1}$ at $20{ }^{\circ} \mathrm{C}$ with an IEC of $2.1 \mathrm{mmol} \mathrm{g}{ }^{-1}$. Meanwhile, the AEMs also exhibit excellent oxidative stability in Fenton's reagent for $200 \mathrm{~h}$ and alkaline stability in $1 \mathrm{~mol} \mathrm{~L}^{-1} \mathrm{KOH}$ at $60{ }^{\circ} \mathrm{C}$ for $480 \mathrm{~h}$. Furthermore, the peak power density of an $\mathrm{H}_{2} / \mathrm{O}_{2}$ single fuel cell is up to $54 \mathrm{~mW} \mathrm{~cm}^{-2}$.

\section{Introduction}

Anion exchange membrane fuel cells (AEMFCs) have received more and more attention because of their superiority to proton exchange membrane fuel cells (PEMFCs), especially the use of non-precious metals, fast electrode kinetics and excellent corrosion resistance of metal materials under basic conditions and so on. ${ }^{1-4}$ As a key component in an AEMFC, the anion exchange membrane (AEM) faces a trade-off between ionic conductivity, mechanical strength and chemical stability, ${ }^{3,5}$ which is more serious than that in proton exchange membranes owing to the inherently lower conductivity of $\mathrm{OH}^{-}$(the conductivity ratio of $\mathrm{H}^{+} / \mathrm{OH}^{-}$is about 1.76 (ref. 6)) and easy degradation of quaternary ammonium (QA) cationic groups. ${ }^{7}$

It is well known that the balance between chemical stability and ionic conductivity of AEMs is mainly reliant on the structure of AEMs, ion exchange capacity (IEC) and types of functional groups. ${ }^{8}$ High IEC always leads to a better hydration hydroxyl network for Grotthuss transport, ${ }^{9}$ but concurrently leads to high water uptake, severe swelling and poor strength. ${ }^{8}$ To conquer this trade-off, many strategies have been put forward to improve both high ionic conductivity, dimensional and mechanical stability, such as crosslinking, ${ }^{3,5,10}$ and selfaggregation strategy. ${ }^{11}$ Several researchers have found that

${ }^{a}$ Fuel Cell System and Engineering Group, Dalian Institute of Chemical Physics, Chinese Academy of Sciences, 457 Zhongshan Road, 116023 Dalian, PR China. E-mail: zhgshao@dicp.ac.cn; Fax: +86 411 84379185; Tel: +86 41184379153

${ }^{b}$ University of Chinese Academy of Sciences, 100049 Beijing, PR China crosslinking by introducing chemical or physical cross-links in the system is an effective way to enhance the dimensional stability without separation of the different components. ${ }^{12} \mathrm{Lu}$ et al. reported PVBC/PBI (poly(vinylbenzyl chloride)/ polybenzimidazole) crosslinked AEM which exhibited a high conductivity of $25 \mathrm{mS} \mathrm{cm}{ }^{-1}$ at $30^{\circ} \mathrm{C}$ with a lower swelling ratio of $13 \% .^{3}$ Lai et al. prepared the phenolphthalein-containing poly(arylene ether sulfone)s crosslinked AEMs showed a high IEC of $1.91 \mathrm{mmol} \mathrm{g}^{-1}$ while the swelling ratio was less than $15 \% .{ }^{13}$ Unfortunately, it has been reported that the aryl ethercontaining crosslinked AEMs, such as poly(phenylene oxide) $(\mathrm{PPO})^{14,15}$ and polysulfone (PSF), ${ }^{\mathbf{1 6 , 1 7}}$ would be severely degraded by cleavage of the $\mathrm{C}-\mathrm{O}$ bonds via ether hydrolysis and/or QA group hydrolysis under high $\mathrm{pH}$ conditions. ${ }^{18,19}$

Besides, except from the ionic conductivity of AEMs, chemical stability, especially for functional groups, is still considered to be a tough challenge. ${ }^{8} \mathrm{QA}^{20}$ is most widely used in AEMs and shows great influences on hydroxide conductivity. However, QA groups exhibit different alkaline stabilities when attached to different polymer backbones, such as PPO, poly(arylene ether sulfone) (PAES), and PSF, mainly attribute to the degradation via Hofmann elimination and/or nucleophilic substitution reaction through $\beta$-hydrogens. ${ }^{\mathbf{8} 21}$ Various cationic functional groups are the widely used to improve the stability of AEMs, such as imidazolium, ${ }^{\mathbf{1 , 8}}$ highly alkaline phosphonium, ${ }^{22,23}$ guanidine $^{24}$ and so on. Among them, imidazolium functional groups which have a p-conjugated imidazole ring can reduce the reactions of the $\mathrm{S}_{\mathrm{N}} 2$ substitution, Hofmann elimination 
reactions and/or ylide formation ${ }^{25}$ and have been the topic of extensive research in the past few years., ${ }^{2,26-28}$

However, experimental evidences have indicated that imidazolium functional groups face considerable alkaline degradation when grafted directly to polymer backbones. ${ }^{25}$ By selecting the appropriate substituents, the degradation of imidazolium functional groups can be inhibited to some extent. ${ }^{20,25}$ Recently, most of researches are all focus on the stability investigation of the C2substituted imidazolium cations via the analysis of ${ }^{1} \mathrm{H}$ NMR to small molecule compounds ${ }^{1,26}$ and have been suggested that steric interference at $\mathrm{C} 2$ position has a significant impact on the improvement of stability. ${ }^{28}$ However, most studies show C2substituted imidazolium cations still exist the problems of degradation by $\mathrm{OH}^{-}$attacks. ${ }^{26}$ Varcoe $e t ~ a l$. recently reported that the conductivity and IEC of the 1,2-dimethylimidazolium-based AEMs would degrade greatly in $1 \mathrm{M} \mathrm{KOH}$ at $60{ }^{\circ} \mathrm{C}$ (ref. 29) and the same results are found by Yang ${ }^{25}$ which found the conductivity of 1,2-dimethylimidazolium functionalized styrene polymeric AEMs would diminish in $1 \mathrm{M} \mathrm{KOH}$ at $60{ }^{\circ} \mathrm{C}$ after $100 \mathrm{~h}$. Besides, recent researches reported the N1-alkyl and C2substituted imidazolium cations to further improve the stability of AEMs. ${ }^{25}$ Density functional theory (DFT) calculations by Pivovar $^{30}$ or others ${ }^{31-33}$ predict the positive influence of C4, C5 substituents of imidazolium. Nowadays, Coates and co-workers ${ }^{27}$ systematically evaluated the small imidazolium molecules with different substitution on N1, N2, C2, C4, C5 position. They confirmed that $\mathrm{C} 4$ and $\mathrm{C} 5$ methyl substituted imidazolium exhibited the highest alkaline stability and the residual conductivity was higher than $99 \%$ after the exposure to $5 \mathrm{M} \mathrm{KOH}$ at $80^{\circ} \mathrm{C}$ for 30 days. ${ }^{27}$ They also found that $\mathrm{C} 4,5$ substitution with methyl groups slightly improving the stability relative to phenyl groups and long chain alkyl substituents on N1 position had a more favorable influence on preventing degradation of imidazolium better than benzyl or methyl groups ${ }^{27}$ which was agree with the results obtained by Zhang ${ }^{34}$ and Yan. ${ }^{35}$ Unfortunately, the influence of C4, C5 substituents on the stability of imidazolium functional AEMs is not too much and deep research. Thus it is necessary for functional groups with high stability to be located on a more stable backbone of polymers under high pH condition in AEMFCs. ${ }^{7}$

Herein, a novel N1-butyl substituted 4,5-dimethyl-imidazole (BDIm) is synthesized with the purpose to improve the stability of AEMs by steric hindrance and (or) hyperconjugative effects. Using the novel BDIm, we prepared a series of poly(vinylbenzyl chloride) (PVBC)/polybenzimidazole (PBI) crosslinked AEMs containing BDIm groups with high alkaline-resistant and dimension stability. The influences of the crosslinked structure between backbone polymers and BDIm on physical and chemical properties are investigated in detail. Besides, the corresponding membrane is fabricated to the membrane electrode assembly (MEA) and is tested in a single AEMFC.

\section{Experimental}

\section{Materials}

4,5-Dimethyl- $1 \mathrm{H}$-imidazole hydrochloride (DIm) was purchased from Wuhan Taikaisai Scientific Co., China. Butyl bromide was purchased from Sigma-Aldrich. Polybenzimidazole (PBI, the inherent viscosity of $2.43 \mathrm{dL} \mathrm{g}^{-1}$ (ref. 36)) was synthesized by the method mentioned in our previous works ${ }^{36}$ and identified by ${ }^{1} \mathrm{H}$ NMR in DMSO- $\mathrm{d}_{6}$ (Fig. 2a). Poly vinylbenzyl chloride (PVBC, 60/ 40 mixture of 3- and 4-isomers with average molecular weight $M_{\mathrm{n}} \sim 55000$, average $M_{\mathrm{w}} \sim 100000$ by GPC/MALLS, powder) was procured from Aldrich and identified by ${ }^{1} \mathrm{H}$ NMR in DMSO- $\mathrm{d}_{6}$ (Fig. 2b). Sodium hydride $(60 \% \mathrm{w} / \mathrm{w}$ in mineral oil) was purchased from Aladdin Industrial Inc. And $N, N$-dimethylformamide (DMF), $N$-methyl-2-pyrrolidone (NMP), ethyl acetate (EtOAc) and other chemicals were commercially available with analytical grade. Besides, the electrocatalyst used in the fuel cell testing was Pt/C (70\% Pt on Vulcan XC-72 carbon) and 60\% $\mathrm{PtRu} / \mathrm{C}$, which was supplied from Johnson Matthey Co. Deionized (DI) water was used in the experiments.

\section{Synthesis of 1-butyl-4,5-dimethyl-imidazole (BDIm)}

BDIm was synthesized by DIm and butyl bromide via a modified way referred to literature. ${ }^{37,38}$ Typically, $2 \mathrm{~g}$ (0.015 mol) DIm was dissolved in $10 \mathrm{~mL}$ DMF at $0{ }^{\circ} \mathrm{C}$, and then $1.44 \mathrm{~g}$ (2.4 times the molar amount of DIm) sodium hydride was slowly added into the solution. After heating at $0{ }^{\circ} \mathrm{C}$ for $0.5 \mathrm{~h}$ under stirring, $3.08 \mathrm{~g}(0.023 \mathrm{~mol})$ butyl bromide was added in the above solution and was stirred for $3 \mathrm{~h}$ at room temperature. The solution mixture was separated by precipitation the mixture in DI water, followed by thorough extracting with ethyl acetate several times. Finally, the crude products were purified by the column chromatography method with EtOAc as the separation agent to obtain the desired BDIm. The synthetic routes are shown in Fig. 1.

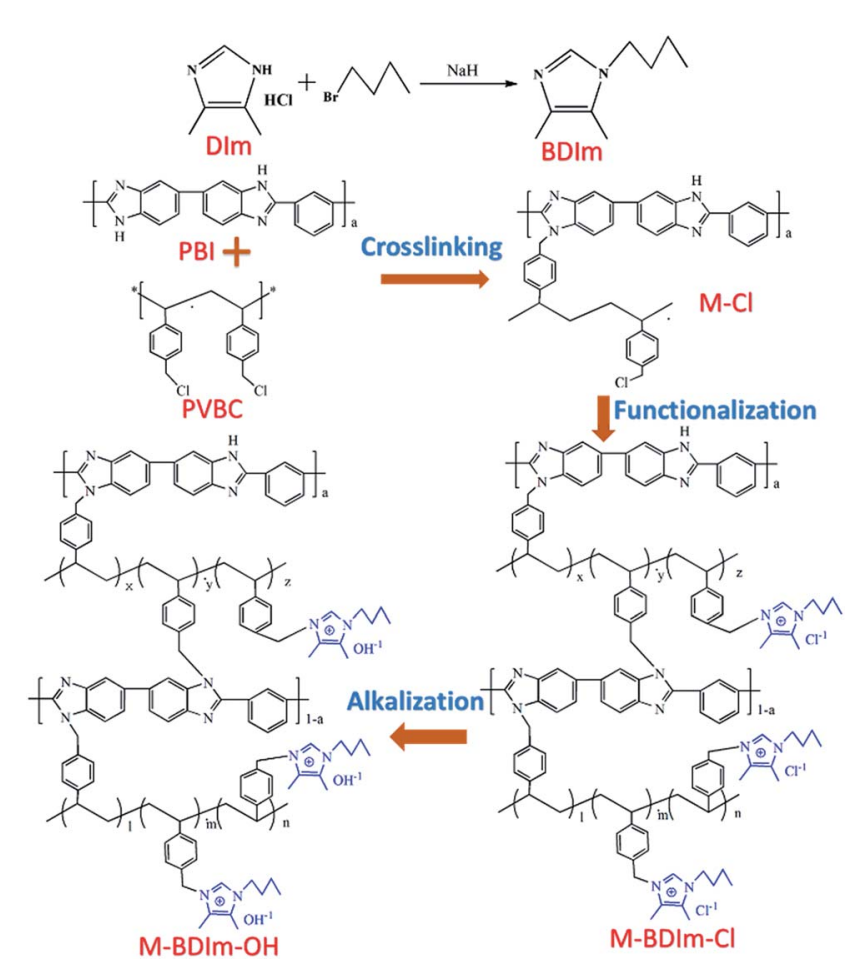

Fig. 1 The diagram for preparation of $\mathrm{BDIm}$ and $\mathrm{M}-\mathrm{BDIm}-\mathrm{OH}$. 


\section{Preparation of BDIm functionalized membranes}

The preparation procedure of the BDIm functionalized PVBC membranes crosslinked by PBI were synthesized by the nucleophilic substitution reaction. The membranes were prepared by two steps as shown in Fig. 1, including preparation of PVBC membranes crosslinked by PBI and functionalization. Briefly, PBI was completely dissolved in the NMP followed by adding PVBC with the mass ratio of PBI and PVBC of $1: 1,3: 2,2: 1$ and $3: 1$. After complete dissolution, the mixed polymer solution were cast on a glass plate and dried on a hot plate at $80^{\circ} \mathrm{C}$. In first $24 \mathrm{~h}$, a glass cover was covered on the solution to slow down the evaporation rate to make the crosslinking to react thoroughly. After $24 \mathrm{~h}$, the glass cover was taken away and the solution was dried at $80{ }^{\circ} \mathrm{C}$ in the air for $24 \mathrm{~h}$. The PVBC membranes crosslinked by PBI obtained was denoted as M-Cl- $x: y$ ( $x: y$ was the mass ratio of PBI and PVBC of $1: 1,3: 2,2: 1$ and $3: 1$ ). Subsequently, to make the $-\mathrm{CH}_{2} \mathrm{Cl}$ groups be converted into imidazolium groups, the $\mathrm{M}-\mathrm{Cl}$ $x: y$ were functionalized by immersing in $0.5 \mathrm{~mol} \mathrm{~L}^{-1}$ BDIm ethanol solution for $48 \mathrm{~h}$ at $60^{\circ} \mathrm{C}$, named as M-BDIm-Cl- $x: y$. After that, the membranes in $\mathrm{OH}^{-}$form were obtained by soaking the M-BDIm-Cl- $x: y$ in $1 \mathrm{~mol} \mathrm{~L}^{-1} \mathrm{KOH}$ solution at room temperature for two days, converting the membranes from the $\mathrm{Cl}^{-}$form into the $\mathrm{OH}$ form $(\mathrm{M}-\mathrm{BDIm}-\mathrm{OH}-x: y)$. Then, the membranes were taken out from the alkaline liquor and washed by DI water several times and storing in DI water to remove the residual $\mathrm{KOH}$ prior to further experiments. Besides, the thickness of the M-BDIm-OH membranes were about $25 \mu \mathrm{m}$.

\section{Structure characterization}

The ${ }^{1} \mathrm{H}$ NMR spectra were carried out on Bruker Avance III 400 NMR spectrometer, using deuterated dimethylsulfoxide (DMSO$\left.\mathrm{d}^{6}\right)$ as the solvent and tetramethylsilane (TMS) as the internal standard. Fourier-transform infrared (FT-IR) of M-BDIm-Cl and MBDIm-OH membranes were recorded at a resolution of $4 \mathrm{~cm}^{-1}$ with a Bruker Equinox 55 FT-IR spectrometer after drying at $60{ }^{\circ} \mathrm{C}$ under vacuum overnight. The morphology of the surface and cross-section of the membrane samples were recorded with the field emission scanning electron microscope (FESEM, Zeiss JEM$2100 \mathrm{~F}$ ). And the elemental analysis of samples was conducted by Oxford Inca EDX detector equipped on the FESEM. Before examination, to distinguish the covalently bonded $\mathrm{Cl}_{\text {with }} \mathrm{Cl}^{-}$ions of M-BDIm-Cl-1 : 1, the samples were carried out after exchanging $\mathrm{Cl}^{-}$with $\mathrm{Br}^{-}$ions and fractured with liquid $\mathrm{N}_{2}$ and then sprayed with gold. The mechanical properties of the dry membranes in the $\mathrm{OH}^{-}$form were characterized by the electrical universal test machine (Changchun Kexin Co., China) at a speed of $5 \mathrm{~mm} \mathrm{~min}^{-1}$. The thermal stability of the membranes was investigated on a thermogravimetric analyser (DSC-Q1000, USA) with a heating rate of $10^{\circ} \mathrm{C} \mathrm{min}^{-1}$ in a temperature range from room temperature to $700{ }^{\circ} \mathrm{C}$ under nitrogen atmosphere.

\section{Ionic exchange capacity (IEC), water uptake (WU) and swelling ratio (SR)}

The IEC of membrane samples were determined by the classical back titration method., Firstly, the membranes in $\mathrm{OH}^{-}$form were dried at $50{ }^{\circ} \mathrm{C}$ under vacuum for $48 \mathrm{~h}$. The membranes were immersed in $\mathrm{HCl}$ solution for $72 \mathrm{~h}$ in order to make sure that all the $\mathrm{OH}^{-}$ions of the membranes were transmuted into $\mathrm{H}^{1+}$ ions. After that, the residual $\mathrm{H}^{1+}$ ions were back titrated with a back titrated method using $0.01 \mathrm{~mol} \mathrm{~L}^{-1} \mathrm{NaOH}$ solution in the presence of an indicator (phenolphthalein). And then the membrane was immersed in DI water and dried in a vacuum at $60{ }^{\circ} \mathrm{C}$ for $24 \mathrm{~h}$ to achieve a certain weight. And the IEC (mmol $\mathrm{g}^{-1}$ ) of the membranes was calculated as follows:

$$
\mathrm{IEC}=\frac{\mathrm{M}_{\mathrm{b}, \mathrm{HCl}}-\mathrm{M}_{\mathrm{a}, \mathrm{HCl}}}{m}
$$

where $\mathbf{M}_{\mathrm{b}, \mathrm{HCl}}$ and $\mathbf{M}_{\mathrm{a}, \mathrm{HCl}}$ were the amount of $\mathrm{HCl}$ in $\mathrm{mmol}$ before and after titration with $\mathrm{NaOH}$, respectively; and $m$ was the weight of the dried membranes.

To investigate the WU and SR of the membranes as a function of temperature $\left(20-80{ }^{\circ} \mathrm{C}\right)$, pieces of the membranes were immersed in DI water and equilibrated at each temperature. Equilibrated membranes were wiped quickly with tissue paper to remove water on the surface, and then, measured the mass, width, and length of the fully hydrated membranes. The mass, width, and length of the dry membrane were determined after drying in a vacuum oven at $50{ }^{\circ} \mathrm{C}$ for $48 \mathrm{~h}$. The WU and SR of membranes were calculated by equations:

$$
\begin{aligned}
& \mathrm{WU}(\%)=\frac{M_{\text {wet }}-M_{\text {dry }}}{M_{\text {dry }}} \times 100 \% \\
& \operatorname{SR}(\%)=\frac{\left(L_{\text {wet }} \times B_{\text {wet }}\right)^{1 / 2}-\left(L_{\text {dry }} \times B_{\text {dry }}\right)^{1 / 2}}{\left(L_{\text {dry }} \times B_{\text {dry }}\right)^{1 / 2}} \times 100 \%
\end{aligned}
$$

where $M_{\text {wet }}, L_{\text {wet }}$ and $B_{\text {wet }}$ were the mass, length and width length of wet membrane, respectively; $M_{\mathrm{dry}}, L_{\mathrm{dry}}$ and $B_{\mathrm{dry}}$ were the mass, length and width length of dry membrane, respectively.

\section{Membrane conductivity measurement}

The conductivity of the membranes was measured under fully hydrated condition by a two-probe AC impedance method using a cell with a pair of pressure-attached copper electrodes by a Solartron 1260 \& 1287 electrochemical workstation under the potentiostatic mode. ${ }^{3}$ The measurement was conducted in a frequency range from $10^{6}$ to $100 \mathrm{~Hz}$ at a voltage amplitude of $10 \mathrm{mV}$ in the DI water with $\mathrm{N}_{2}$ saturated. To minimize the influence of $\mathrm{CO}_{2}$, the membranes in $\mathrm{OH}^{-}$form were immersing into DI water with $\mathrm{N}_{2}$ saturated at various temperatures ranging from 20 to $80{ }^{\circ} \mathrm{C}$ in a chamber. The conductivity values $(\sigma$, $\mathrm{mS} \mathrm{cm}^{-1}$ ) was calculated by the following equation: ${ }^{36,39}$

$$
\sigma=\frac{L}{R d w}
$$

where $L(\mathrm{~cm})$ was the distance between the two electrodes, $R$ was the membrane resistance by the impedance value at 0 phase angle, $d$ and $w$ were the thickness and width of the membrane, respectively.

\section{Membrane durability studies}

The long-term alkaline stability of M-BDIm-OH-1 : 1 membrane was evaluated by immersing the membrane in $1 \mathrm{~mol} \mathrm{~L}^{-1} \mathrm{KOH}$ at 
$60{ }^{\circ} \mathrm{C}$ to determine the change in the hydroxide conductivity, dimension and IEC values of the membranes. The hydroxide conductivity of the membrane was measured at $30{ }^{\circ} \mathrm{C}$ by the method mentioned above at a certain time interval.

The oxidative stability of the M-BDIm-OH membranes was evaluated by soaking the membrane in Fenton's reagent. The membrane was dried and weighed, and then soaked into $30 \mathrm{~mL}$

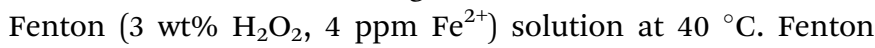
solution was refreshed every 24 hours, and the degraded samples were measured on an electronic balance after absorbing the superficial liquid with filter paper. For comparison, a pure PBI membrane was fabricated and tested by the same method.

\section{Membrane electrode assembly (MEA) and single cell performance}

The performances of M-BDIm-OH-1 : 1 membrane were further evaluated in a single AEMFC. Two gas diffusion electrode (GDE) and membrane with effective area $5 \mathrm{~cm}^{2}$ were pressed at room temperature to form the membrane electrode assembly (MEA). And the PtRu/C (60\%, JM Co.) loading of the anode and $\mathrm{Pt} / \mathrm{C}$ (70\%, JM Co.) loading of the cathode were both $0.4 \mathrm{mg} \mathrm{cm}^{-2}$, respectively. Fuel cell tests were estimated under the operating temperature of $50{ }^{\circ} \mathrm{C}$ with hydrogen and oxygen gas for both anode and cathode feeds at $0.1 \mathrm{MPa}$ with $100 / 200 \mathrm{~mL} \mathrm{~min}{ }^{-1}$, respectively. The polarization curves of AAEMFCs were evaluated by an electric load system (KMF2030, Kikusui Electronics Corp.) and Solartron 1260 workstation. The EIS experiments were carried out at a current between $10 \mathrm{~mA}$ to $500 \mathrm{~mA}$ with a small amplitude alternating voltage of $10 \mathrm{mV}$ and the frequency range was from $10 \mathrm{kHz}$ to $0.1 \mathrm{~Hz}$.

\section{Results and discussion}

\section{Preparation and structure analysis of the BDIm functionalized crosslinked membranes}

4,5-Dimethyl-1 $H$-imidazole hydrochloride (DIm) was reacted with butyl bromide to synthesize the BDIm and purified by the column chromatography. The structure of the as-synthesized

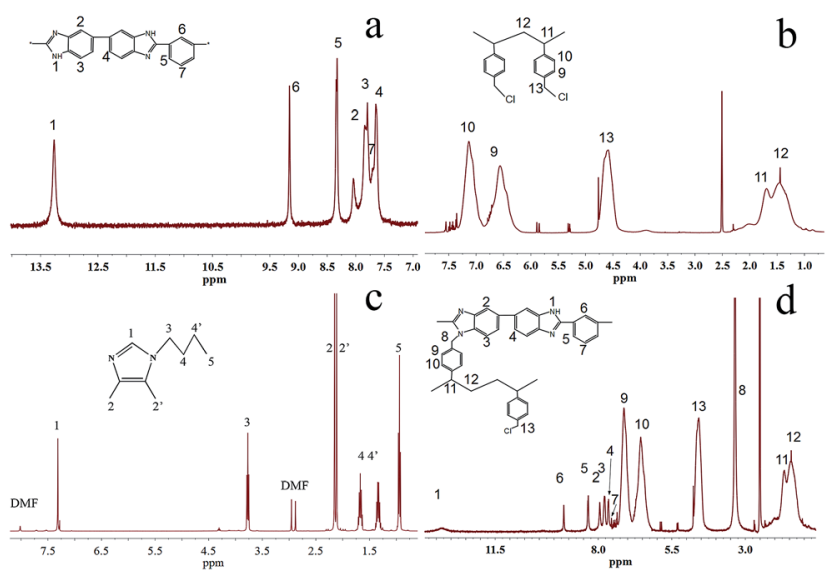

Fig. $2{ }^{1} \mathrm{H}$ NMR spectroscopy of PBI (a), PVBC (b), BDIm (c) and $\mathrm{M}-\mathrm{Cl}$ (d).
BDIm is shown in Fig. 1. As confirmed by ${ }^{1} \mathrm{H}$ NMR analysis in Fig. 2c, the signal at 2.01, 2.07 ppm are ascribed to methyl at C4, C5 and the $\mathrm{H}_{3}-\mathrm{H}_{5}$ are correspond to protons of butyl. The welldefined peaks indicate that the successful synthesis of BDIm. The overall synthetic procedure for $\mathrm{M}-\mathrm{BDIm}-\mathrm{OH}$ was mainly divided into three parts, involving the preparation of PVBC membranes crosslinked by PBI, BDIm functionalization and alkalization, as shown in Fig. 1.

PBI, with good mechanical properties and thermal stabilities, is used as a macromolecular crosslinker to interconnect with PVBC. So to identify the crosslinking reaction, PBI and PVBC were dissolved in DMSO- $\mathrm{d}^{6}$ and heated for $12 \mathrm{~h}$, and then, recorded in ${ }^{1} \mathrm{H}$ NMR (Fig. 2d). Compared with ${ }^{1} \mathrm{H}$ NMR of PBI (Fig. 2a) and PVBC (Fig. 2b), the new peak at 3.35 of 8 (marked in Fig. 2d) can confirmed the crosslinking reaction of $\mathrm{M}-\mathrm{Cl}$, which is agree with the results obtained by our previous works. ${ }^{3}$ So a series of $\mathrm{M}-\mathrm{Cl}$ are prepared with the mass ratio of $\mathrm{PBI}$ and PVBC of $1: 1,3: 2,2: 1$ and $3: 1$. Subsequently, to make the $-\mathrm{CH}_{2} \mathrm{Cl}$ groups be converted into imidazolium groups, $\mathrm{M}-\mathrm{Cl}$ was functionalized by immersing in $0.5 \mathrm{~mol} \mathrm{~L}^{-1}$ BDIm ethanol solution for $48 \mathrm{~h}$ at $60{ }^{\circ} \mathrm{C}$, named as M-BDIm-Cl and followed by converting into the $\mathrm{OH}^{-}$form (M-BDIm-OH). The basic parameters of $\mathrm{M}$-BDIm-OH with different ratio is shown in Table 1 and the overall synthetic procedure for the AEMs is illustrated in Fig. 1.

Due to the insolubility of M-BDIm-OH, the chemical structures of M-Cl-1 : 1, M-BDIm-Cl-1 : 1 and M-BDIm-OH-1 : 1 were characterized by FT-IR, shown in Fig. 3 . The FT-IR spectrum of M-Cl-1 : 1 exhibited the characteristic absorption bands at $1265 \mathrm{~cm}^{-1}$ is attributed to stretching vibrations of unreacted $\mathrm{CH}_{2}-\mathrm{Cl}$ groups of PVBC. ${ }^{40}$ And the peaks at $800 \mathrm{~cm}^{-1}$, $1666 \mathrm{~cm}^{-1}$ and $1446 \mathrm{~cm}^{-1}$, which are assigned to the stretch vibration in plane of $\mathrm{C}=\mathrm{C}$ and $\mathrm{C}=\mathrm{N}$ groups, can be ascribed to the existence of $\mathrm{PBI}{ }^{36}$

Compared with M-Cl-1 : 1, BDIm is introduced confirmed by the disappearance of the absorption peak at $1265 \mathrm{~cm}^{-1}$ in MBDIm-Cl-1: 1 and M-BDIm-OH-1 : 1 . And the peak at about $736 \mathrm{~cm}^{-1}$ in M-BDIm-Cl-1 : 1 and M-BDIm-OH-1 : 1 is assigned to the vibration of $\mathrm{C}-\mathrm{N}$ bond in imidazolium cations. ${ }^{7,20}$ Besides, the strong absorption bands near $1560 \mathrm{~cm}^{-1}$ and $1602 \mathrm{~cm}^{-1}$ are mainly ascribed to the stretching vibration of the $\mathrm{C}-\mathrm{H}$ of butyl. All these differences of FT-IR spectral data definitely confirm the successful introduction of BDIm into M-Cl$1: 1$.

The thermal degradation behaviour of the M-BDIm-Cl-1 : 1 and $\mathrm{M}-\mathrm{Cl}-1$ : 1 were examined via thermogravimetric analysis (TGA) under a nitrogen atmosphere, shown in Fig. 4. We all know that PBI and PVBC exhibit excellent thermomechanical stability up to $\sim 600{ }^{\circ} \mathrm{C}$ and $\sim 350{ }^{\circ} \mathrm{C}$ which is mentioned by our previous works. ${ }^{3}$

In the TG curves of M-BDIm-Cl-1:1 and M-Cl-1:1, the weight loss before $150{ }^{\circ} \mathrm{C}$ may due to bonded water and residual solvent, which is followed by a new weight loss step. The new weight loss from $150{ }^{\circ} \mathrm{C}$ to $200{ }^{\circ} \mathrm{C}$ is probably due to the degradation of crosslinking point formed between PBI and $-\mathrm{CH}_{2}-\mathrm{Cl}$ groups. ${ }^{3}$ In the TG curve of M-BDIm-Cl-1 : 1 , the new step from $210{ }^{\circ} \mathrm{C}$ to $370{ }^{\circ} \mathrm{C}$ can be attribute to the 
Table 1 IEC, SR, WU, hydroxide conductivities and mechanical characteristics of the M-BDIm-OH

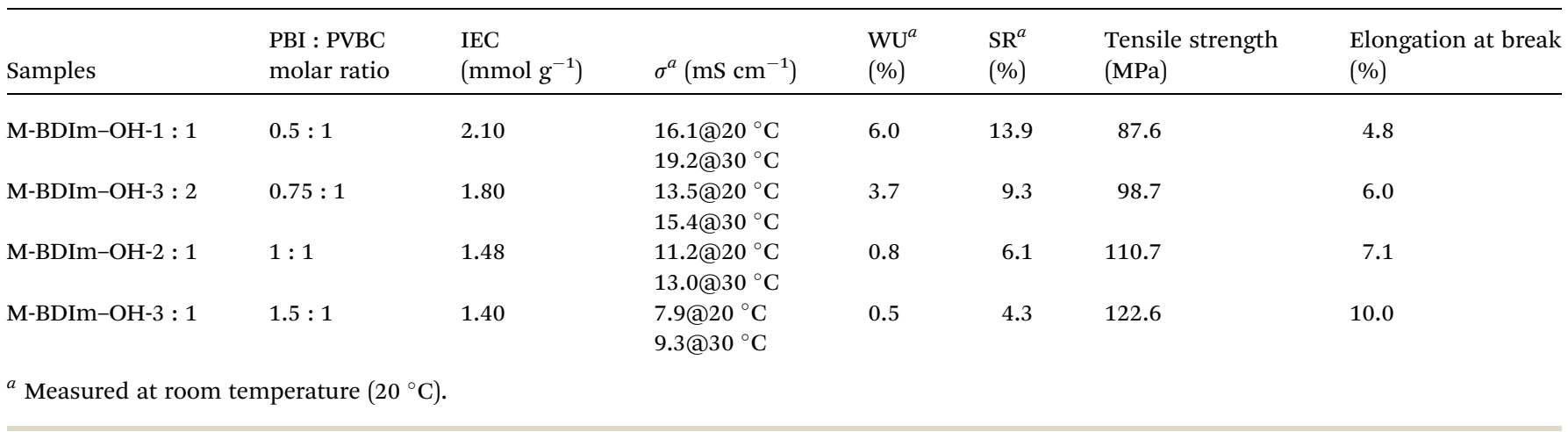

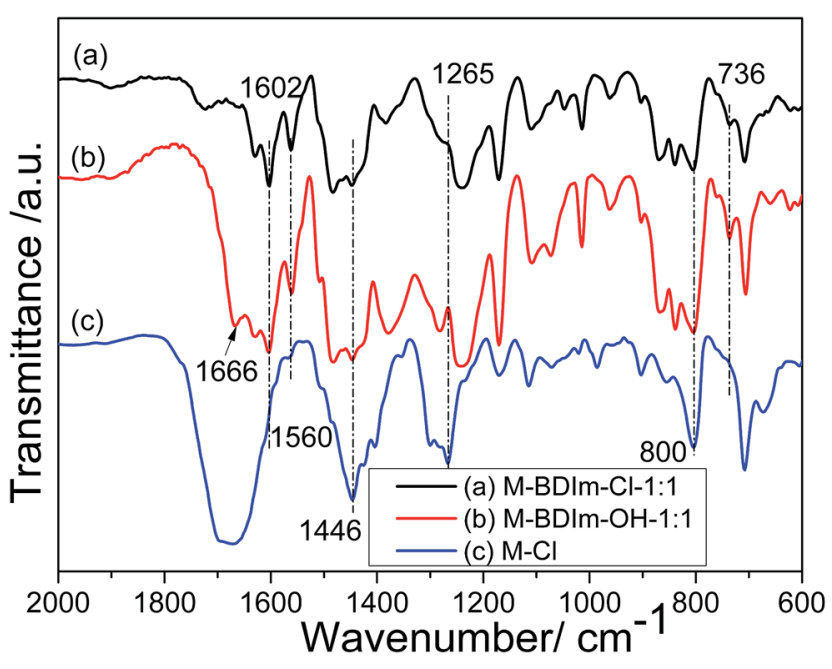

Fig. 3 FTIR spectra of membranes.

decomposition to BDIm cations and butyl. And the decomposition of main-chain of PVBC takes place above $450{ }^{\circ} \mathrm{C} .{ }^{3}$ In summary, the $\mathrm{M}$-BDIm-Cl crosslinked membrane exhibits better thermomechanical stability at the operating temperature of AEMFC $\left(50-60{ }^{\circ} \mathrm{C}\right)$.

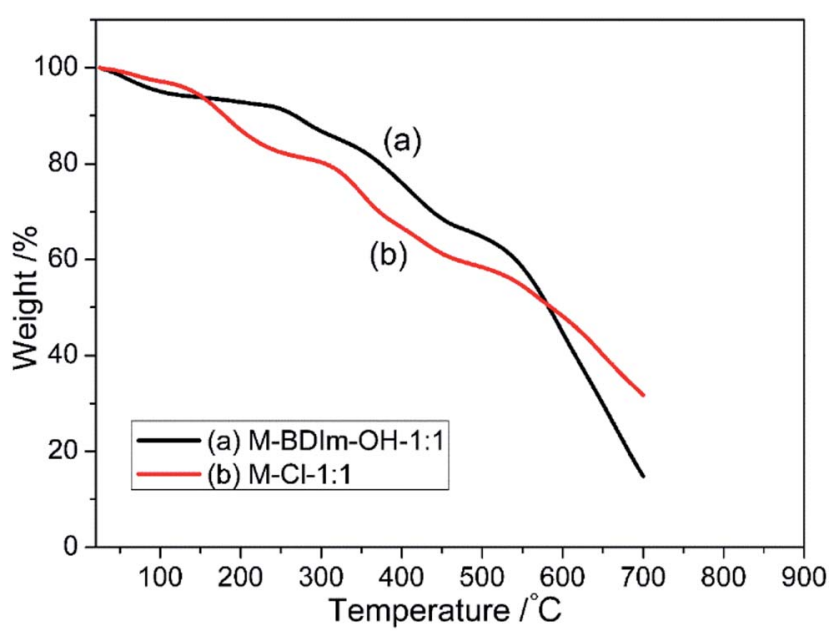

Fig. 4 TG curves for different polymers under $\mathrm{N}_{2}$ atmosphere.

\section{Morphology of the M-BDIm-OH crosslinked membranes}

The surface and cross-section FESEM images of the M-BDImOH-1 : 1 are presented in Fig. 5e-g. M-BDIm-OH-1: 1 shows a uniform and homogeneous morphology and the cross-section of M-BDIm-OH-1:1 reveals the formation of a compact and faultless structure with the thickness of about $25 \mu \mathrm{m}$. In fact, the apparent separation may occur for the AEMs with different components, which can bring the negative effect on the mechanical properties or the ability of ionic conduction. ${ }^{5}$ And in order to confirm the adequacy of functionalization of BDIm, the $\mathrm{Cl}$ elements distribution of $\mathrm{M}$-BDIm-Cl-1 $: 1$ were record by EDX. Before examination, the $\mathrm{Cl}^{-}$ions of M-BDIm-Cl-1 : 1 was exchanged to $\mathrm{Br}^{-}$. From the EDX in Fig. $5 \mathrm{a}$ and b, we can see that the content of covalently bonded $\mathrm{Cl}$ reduce from $75.93 \%$ to $0.5 \%$. It reveals the sufficient conversion of $-\mathrm{CH}_{2} \mathrm{Cl}$ to $-\mathrm{CH}_{2}-$ BDIm. And the uniform and homogeneous morphology exhibited in M-Cl-1 : 1 can confirm the successful formation of the crosslinking structure because that lack of interaction between different components will cause the phase separation. ${ }^{3}$

\section{Analysis of IEC, water uptake (WU) and swelling ratio (SR)}

The IEC, WU, SR and ionic conductivity of M-BDIm-OH are shown in Table 1. IEC value reflects the fixed ion concentration in AEMs and can reflects the properties of AEMs to some extent. $^{25,41}$ The IEC values of M-BDIm-OH were obtained by the back titration method. As shown in Fig. 6a and Table 1, it can be seen that with increasing PVBC mole content from $40 \%$ to $67 \%$, the IEC ranges from 1.20 to $2.10 \mathrm{mmol} \mathrm{g}^{-1}$ because of the increment of BDIm cation groups in the AEMs. The WU and SR of AEMs are equally important parameters and show the same trend in different $\mathrm{PVBC} / \mathrm{PBI}$ mole proportions. Moderate WU is benefit to ion migration, but high WU of AEMs is normally accompanied by over swelling and mechanical weakness. Fortunately, we can see that moderate WU is obtained in MBDIm-OH which is benefit from the crosslinking structure of PBI and PVBC. As listed in Table 1, WU increases from $0.5 \%$ to $6.0 \%$ at room temperature as a result of increments of ionic groups, and SR also follow the same trend. SR of M-BDIm-OH$1: 1$ is only $13.9 \%$, which is much lower than other uncrosslinked AEMs listed in Table 2. The more incorporation of PBI is sought to improve the crosslinking density and rigidity of $\mathrm{M}$ - 

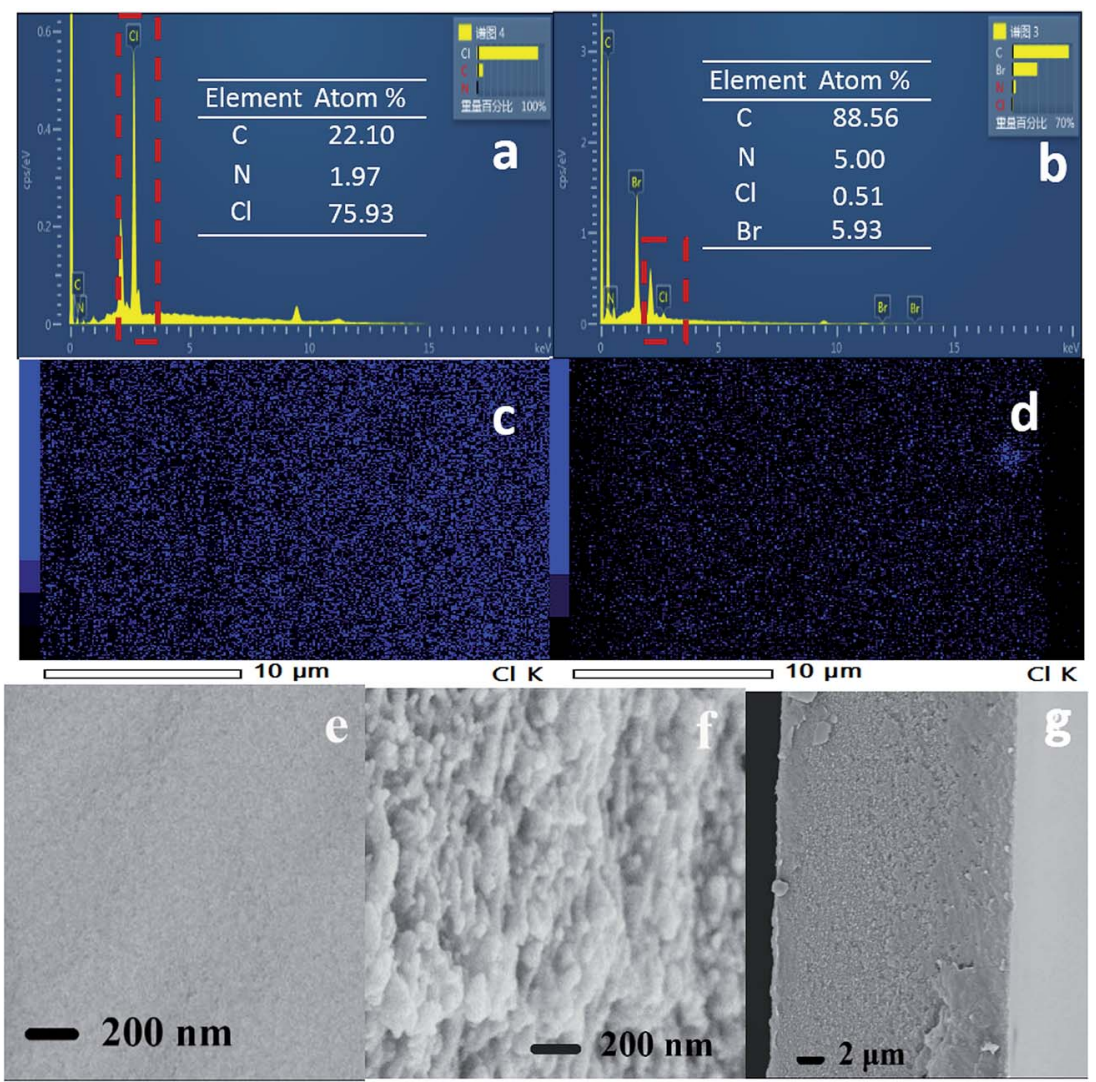

Fig. 5 EDX spectra of (a) M-Cl-1: 1 and (b) M-BDIm-Br-1: 1; the Cl elements distribution of (c) $\mathrm{M}-\mathrm{Cl}-1: 1$ and (d) $\mathrm{M}-\mathrm{BDIm}-\mathrm{Br}-1: 1$; surface (e) and cross-sectional (f, g) SEM images of M-BDIm-OH-1: 1 .
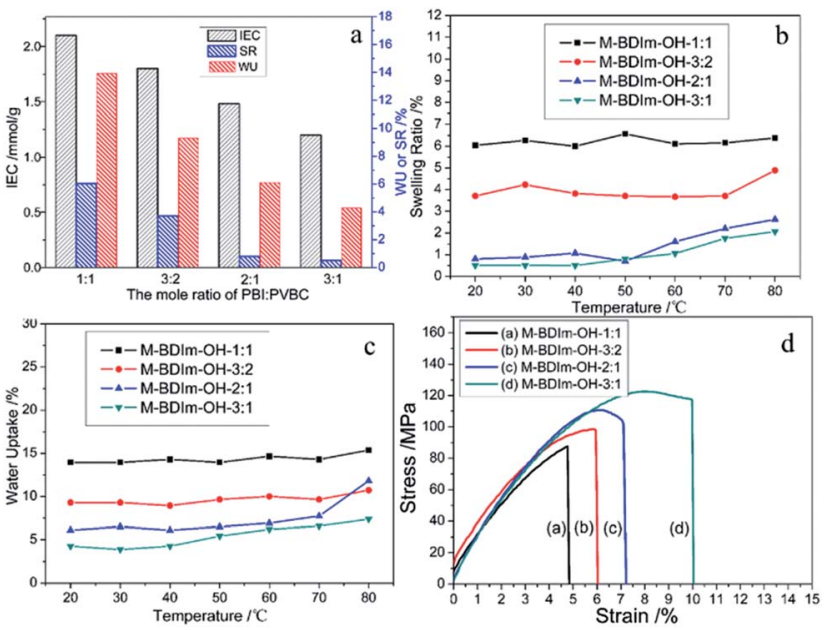

Fig. 6 The IEC, SR and WU of the M-BDIm-OH with different mole ratio of $\mathrm{PBI}$ : $\mathrm{PVBC}(\mathrm{a})$; the changes of $\mathrm{SR}(\mathrm{b})$ and $\mathrm{WU}$ (c) at a function of temperature; stress versus strain curves for $\mathrm{M}-\mathrm{BDIm}-\mathrm{OH}$ (d).

BDIm-OH, resulting in a lower WU and SR, and hence having a higher dimensional stability. Furthermore, WU and SR of MBDIm-OH under different temperatures are measured and shown in Fig. 6b and c. We can see that the WU and SR of MBDIm-OH nearly do not grow vigorously in water under elevated temperature between $20{ }^{\circ} \mathrm{C}$ to $80{ }^{\circ} \mathrm{C}$, which is attribute to the crosslinking of PVBC/PBI. Therefore, M-BDIm-OH provides a potential prospect in development of AEMs with good dimensional stability.

\section{Mechanical properties}

The comparison of mechanical properties of $\mathrm{M}-\mathrm{BDIm}-\mathrm{OH}$ with different PVBC/PBI compositions are shown in Fig. 6d and Table 1. The tensile strength of 87.6 MPa with elongation at break of $4.8 \%$ was obtained in M-BDIm-OH-1: 1 . With the increase of the content of PBI, the tensile strength and elongation of the membranes increase and reach a maximum value of $122.6 \mathrm{MPa}$ and $10.0 \%$ for M-BDIm-OH-3 : 1, respectively. We can see that $\mathrm{M}-\mathrm{BDIm}-\mathrm{OH}$ presents the excellent toughness compared with the homogeneous membranes without crosslinking $^{3}$ and much higher than reported AEMs. ${ }^{20}$

\section{Hydroxide conductivity}

Fig. 7a shows hydroxide conductivity of M-BDIm-OH under different temperatures. In order to minimize the influence of $\mathrm{CO}_{2}$ at various temperatures, the measurement was conducted in the DI water with $\mathrm{N}_{2}$ saturated. We can see that the hydroxide conductivity of $\mathrm{M}$-BDIm-OH is proportional to the IEC and increases from 11.18 to $16.1 \mathrm{mS} \mathrm{cm}^{-1}$ at $20{ }^{\circ} \mathrm{C}$ with increasing IEC form 1.48 to $2.10 \mathrm{mmol} \mathrm{g}^{-1}$. The temperature has a positive effect on hydroxide conductivity because of increasing free 
Table 2 IEC, SR, WU and hydroxide conductivities characteristics of the Im based membranes in other literature

\begin{tabular}{|c|c|c|c|c|c|c|c|}
\hline Membrane & $\begin{array}{l}\text { IEC } \\
\left(\mathrm{mmol} \mathrm{g}^{-1}\right)\end{array}$ & $\sigma\left(\mathrm{mS} \mathrm{cm}^{-1}\right)$ & $\begin{array}{l}\mathrm{WU}^{a} \\
(\%)\end{array}$ & $\begin{array}{l}\mathrm{SR}^{a} \\
(\%)\end{array}$ & $\begin{array}{l}\text { Tensile strength } \\
\text { (MPa) }\end{array}$ & 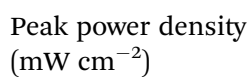 & Ref. \\
\hline M-BDIm-OH-1 : 1 & 2.10 & $\begin{array}{l}16.1 @ 20^{\circ} \mathrm{C} \\
19.2 @ 30^{\circ} \mathrm{C}\end{array}$ & 6.0 & 13.9 & 87.6 & 54 & This works \\
\hline PSAN-[DAMIm] $][\mathrm{Br}]^{b}$ & 1.31 & $11.3 @ 30{ }^{\circ} \mathrm{C}$ & 95.8 & 32.4 & - & - & 28 \\
\hline PVBC/PVA-Im & 1.86 & $21.9 @ 30{ }^{\circ} \mathrm{C}$ & 39.4 & 28.6 & 16 & 37.1 & 20 \\
\hline $\mathrm{C}_{12} \mathrm{VIMBr}^{c}$ & 1.27 & $10.4 @ 20^{\circ} \mathrm{C}$ & 17.1 & 7.57 & - & - & 42 \\
\hline 1.50-PAEK-QM ${ }^{g}$ & 2.17 & $6.7 @ 25{ }^{\circ} \mathrm{C}$ & 10.1 & - & 59.6 & - & 45 \\
\hline PSf135-ImOH ${ }^{h}$ & 2.46 & $20.7 @ 20^{\circ} \mathrm{C}$ & 92.8 & 25.5 & - & 16 & 46 \\
\hline
\end{tabular}

${ }^{a}$ Measured at room temperature $\left(20^{\circ} \mathrm{C}\right) \cdot{ }^{b}$ [DAMIm] [Br] is 1,3-diallyl-2-methyl imidazolium bromine and PSAN is the mixture polymers of styrene, acrylonitrile and benzoin ethyl ether. ${ }^{c} \mathrm{C}_{12} \mathrm{VIMBr}$ is vinyl based polymer with 3 - $n$-alkyl-1-vinylimidazolium bromide. ${ }^{d} \mathrm{PPO}^{-\mathrm{COC}} \mathrm{H}_{10}$-Im is poly $(2,6$ dimethyl-1,4-phenylene oxide) with imidazolium-terminated long side chains. ${ }^{e}$ Measured at $60{ }^{\circ} \mathrm{C} .{ }^{f}$ PAEK/UnIm $0.1 \mathrm{MeIm}_{0.9}$ is poly(aryl ether ketone) with UnIm and MeIm. ${ }^{g}$ 1.50-PAEK-QM is poly(arylene ether ketone) with N1-MeIm. ${ }^{h}$ PSf135-ImOH is polysulfone with methylimidazole.

volume which is benefit to ion transport at higher temperature. $.^{20} \mathrm{M}-\mathrm{BDIm}-\mathrm{OH}-1: 1$ exhibits the highest conductivity of $30.8 \mathrm{~ms} \mathrm{~cm}{ }^{-1}$ at $60{ }^{\circ} \mathrm{C}$, which is meet the conductivity requirement of AEMFCs. ${ }^{5}$ The conductivity of BDIm-OH- $1: 1$ at 20 and $30{ }^{\circ} \mathrm{C}$ reaches 16.1 and $19.2 \mathrm{mS} \mathrm{cm}^{-1}$, which is similar with the other AEMs in the literature, but the SR of M-BDIm$\mathrm{OH}-1: 1$ is much lower than other AEMs listed in Table 2. It should mentioned that the hydroxide conductivity of M-BDImOH-1 : 1 is higher than PVA/PDDA crosslinked membranes of $11.0 \mathrm{mS} \mathrm{cm}{ }^{-1}$ with $76 \% \mathrm{WU}^{47}$ or other AEMs. ${ }^{20}$ But excessive crosslinker content results in the decreasing of hydroxide conductivity due to impose restriction on the mobility of polymer main chain. ${ }^{48}$ What is more, $\mathrm{M}-\mathrm{BDIm}-\mathrm{OH}-3: 1$ possess the
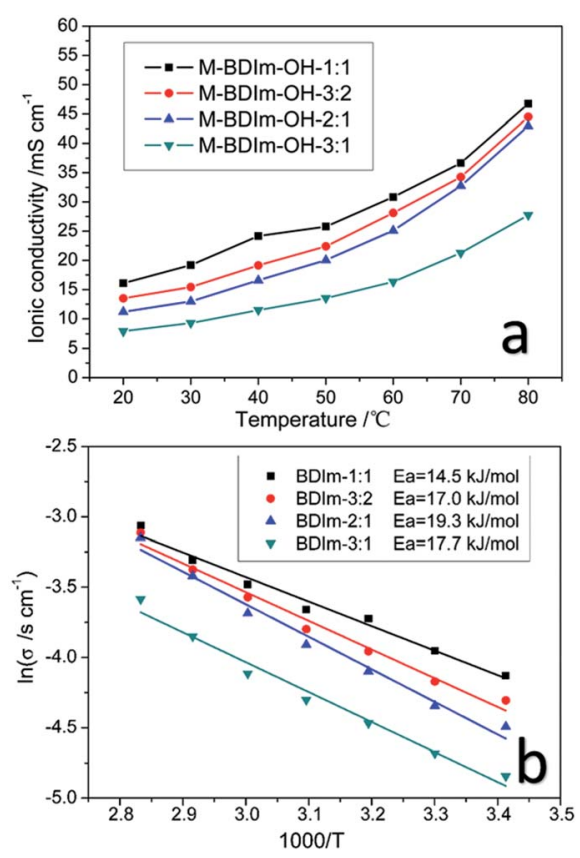

Fig. 7 Hydroxide conductivity of $\mathrm{M}-\mathrm{BDIm}-\mathrm{OH}$ as a function of temperature (a) and Arrhenius plots of $\mathrm{M}-\mathrm{BDIm}-\mathrm{OH}$ at different temperatures (b). lowest WU resulting in the lowest hydroxide conductivity and indicates that fewer water molecules is benefit to hydroxide transport. $^{20}$ Besides, as plotted in Fig. 7b, the hydroxide conductivity of M-BDIm-OH follows an approximate Arrhenius behaviour. The calculated activation energy $\left(E_{\mathrm{a}}\right)$ of $\mathrm{M}-\mathrm{BDIm}-\mathrm{OH}$ varies from 14.5 to $19.3 \mathrm{~kJ} \mathrm{~mol}^{-1}$, which is comparable with other reported AEMs. ${ }^{3,49}$

\section{Chemical stability}

The oxidative stability and long-term alkaline stability of AEM can reflect directly the stability among functional groups and polymers. ${ }^{3,25}$ The mass loss of the M-BDIm-OH was tested in Fenton's reagent and the PBI membrane was also tested for comparison, shown in Fig. 8. We can see that the M-BDIm-OH exhibit an acceptable oxidative stability within $200 \mathrm{~h}$ compared with pure PBI, which is benefit from the crosslinking structure. With the increasing of crosslinker, the oxidative stability of the M-BDIm-OH improves. Besides, in the first $60 \mathrm{~h}$, the mass of MBDIm-OH increases mainly due to the degradation at the aromatic and hydrocarbon backbone under oxidative environment. ${ }^{3}$

The same functional groups induced into different polymer backbone may exhibit different alkaline stability. So, the

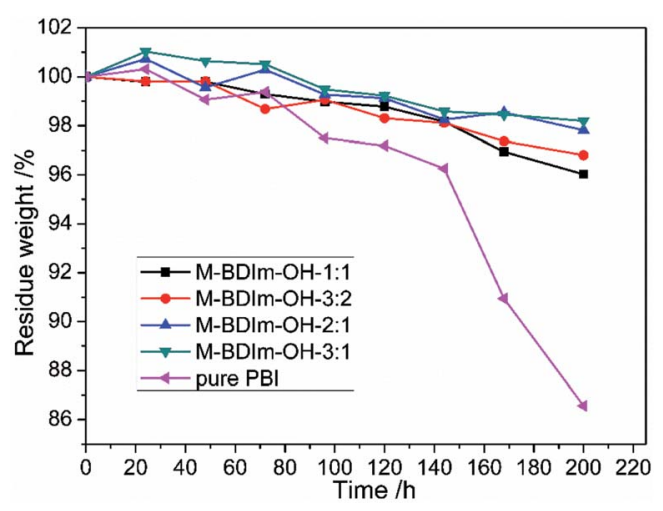

Fig. 8 Accelerated oxidation testing of $\mathrm{M}-\mathrm{BDIm}-\mathrm{OH}$ and $\mathrm{PBI}$. 

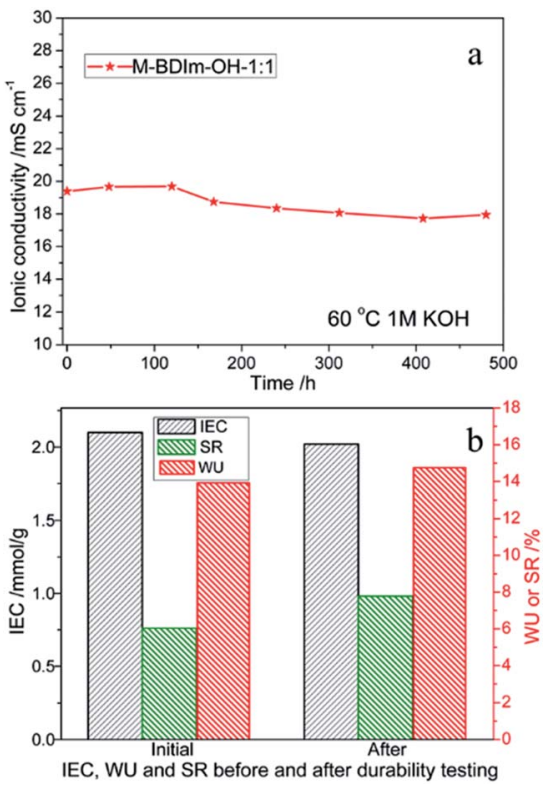

Fig. 9 Accelerated oxidation testing of $\mathrm{M}-\mathrm{BDIm}-\mathrm{OH}$ and $\mathrm{PBI}$.

alkaline stability of the M-BDIm-OH-1 : 1 was evaluated by immersing into $1 \mathrm{~mol} \mathrm{~L}^{-1} \mathrm{KOH}$ at $60{ }^{\circ} \mathrm{C}$ to simulate real environment of AEMFC. From Fig. 9a and Table 3, we can see that the conductivity values, WU and SR of M-BDIm-OH-1 : 1 have not a sharp decline within $480 \mathrm{~h}$ and only $7.4 \%$ conductivity degradation occur during the whole examination process. And IEC values exhibit less than 5\% degradation. The good chemical stability of AEMs depends on the stability of both polymer backbones and functional groups. For polymer backbones, PBI and PVBC contain no ether-based main chain which will be degrade severely in $\mathrm{KOH}$ solution at high temperature due to the hydrolysis and quaternary carbon hydrolysis. ${ }^{25-28}$ And a tight-binding structure is formed by the crosslinking between PBI and PVBC, which has good durability in the high pH environment. ${ }^{3}$ On the other hand, BDIm is used into the PBI/PVBC polymer backbones, with introduced by substitution at the N1, $\mathrm{C} 4$, and $\mathrm{C} 5$ positions. It is believed that C4, 5 substitution with methyl groups slightly improves the stability by steric hindrance and (or) hyperconjugative effects. And long chain alkyl substituents on $\mathrm{N} 1$ position have a more favorable influence on preventing degradation of imidazolium better than benzyl or methyl groups. ${ }^{27,34,35}$ So the obtained membranes achieved a better alkaline stability. It can concluded that the M-BDIm$\mathrm{OH}$ AEMs exhibit an acceptable alkaline and oxidative stability.

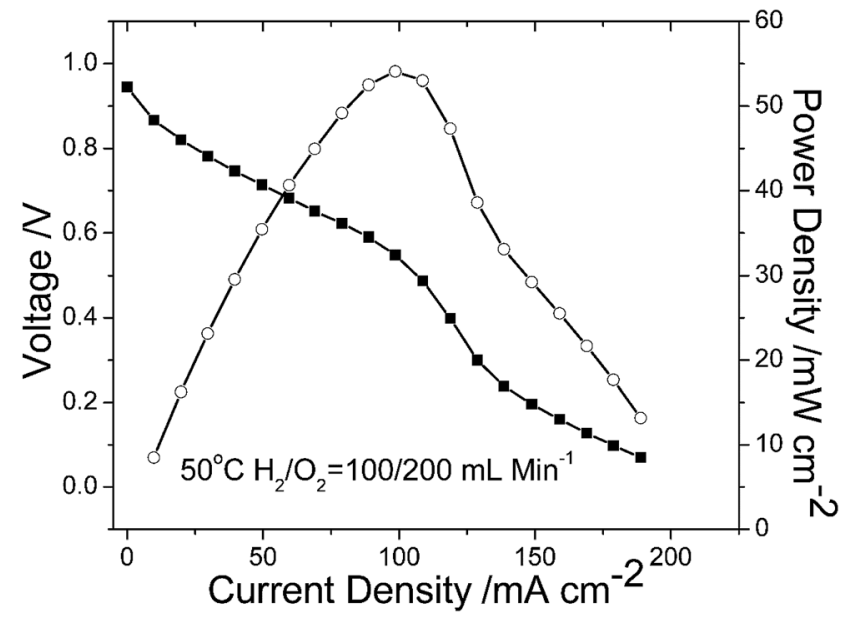

Fig. 10 Fuel cell polarization curve of $\mathrm{M}-\mathrm{BDIm}-\mathrm{OH}-1: 1$.

\section{Single cell performance}

The M-BDIm-OH-1 : 1 shows good physicochemical properties, like good stability, excellent conductivity and good mechanical properties. So M-BDIm-OH-1 : 1 was used for single cell and the polarization curve and power density curve are shown in Fig. 10. The open circuit potential (OCV) is $0.944 \mathrm{~V}$ and it indicates that the obtained membrane has good gas barrier property of AEMs which is more favorable electrochemical reaction kinetics under high $\mathrm{pH}$ condition..$^{20,50}$ And the peak power density of the MEA is $54 \mathrm{~mW} \mathrm{~cm}^{-2}$ at $0.549 \mathrm{~V}$, and is comparable with other AEMs listed in Table 2. Besides, to improve the performance of the AEMFCs, great efforts should be focused on several factors, such as the surface activity of the electrode and the compatibility, the architecture of catalyst layer with good three-phase boundary, MEA fabrication procedure and so on.

\section{Conclusions}

A series of the homogeneous crosslinked PVBC/PBI membranes with 1-butyl-4,5-dimethyl-imidazole (BDIm) were prepared and evaluated as AEMs for fuel cells. BDIm with methyl substituents at C4, C5 and long side alkyl substituents at N1 is firstly synthetized and can greatly enhance the stability by steric hindrance and hyper-conjugative effects resulting in the good alkaline stability of AEMs. The crosslinking structure between PVBC and PBI plays a vital role in achieving both good mechanical, dimension and chemical properties. The M-BDIm$\mathrm{OH}-1$ : 1 is tuned to be an optimal AEM and displays desirable

Table 3 Conductivities changes of $\mathrm{MOH}$ after being exposed to mol $\mathrm{L}^{-1} \mathrm{KOH}$ at $60^{\circ} \mathrm{C}$ for different time

\begin{tabular}{|c|c|c|c|c|c|}
\hline & \multicolumn{5}{|c|}{ Conductivity ${ }^{a} / \mathrm{mS} \mathrm{cm}^{-1}$} \\
\hline & $0 \mathrm{~h}$ & $120 \mathrm{~h}$ & $240 \mathrm{~h}$ & $408 \mathrm{~h}$ & $480 \mathrm{~h}$ \\
\hline
\end{tabular}


performance with the ionic conductivity of $16.1 \mathrm{mS} \mathrm{cm}{ }^{-1}$ at $20{ }^{\circ} \mathrm{C}$, SR of $13.9 \%$ and tensile stress of $87.6 \mathrm{MPa}$. Meanwhile, M-BDIm-OH both has good oxidative stability in Fenton's reagent for $200 \mathrm{~h}$ and has good alkaline stability with only $7.4 \%$ conductivity degradation in $1 \mathrm{~mol} \mathrm{~L}^{-1} \mathrm{KOH}$ at $60{ }^{\circ} \mathrm{C}$ for $480 \mathrm{~h}$, indicating that the obtained AEMs can fulfill the basic conductivity requirement for AEMFCs. The MEA assembled with the optimized M-BDIm-OH-1 : 1 shows the peak power density of $54 \mathrm{~mW} \mathrm{~cm} \mathrm{~cm}^{-2}$ at $0.549 \mathrm{~V}$. Thus, based on the above results, the developed N1-butyl substituted BDIm functionalized PBI/PVBC crosslinked AEMs would be a promising candidate material for fuel cell applications.

\section{Conflicts of interest}

There are no conflicts to declare.

\section{Acknowledgements}

This work was financially supported by the National Key Research and Development Program of China (No. 2016YFB0101208), the National Natural Science Foundation of China (No. U1508202), innovation Program of Key Laboratory of Fuel Cells and Hybrid Power Sources, CAS (No. KLFC201604), CAS-DOE Cooperation Project (No. 121421KYSB20160009), Flanders (FWO) for a fellowship (12F5514N), a Research Grant $(1529816 \mathrm{~N})$ and a travel grant (V410316N) for a Visiting Professorship at the Technical University of Denmark.

\section{References}

1 J. Wang, S. Gu, R. B. Kaspar, B. Zhang and Y. Yan, ChemSusChem, 2013, 6, 2079-2082.

2 O. D. Thomas, K. J. W. Y. Soo, T. J. Peckham, M. P. Kulkarni and S. Holdcroft, J. Am. Chem. Soc., 2012, 134, 10753-10756.

3 W. Lu, G. Zhang, J. Li, J. Hao, F. Wei, W. Li, J. Zhang, Z.-G. Shao and B. Yi, J. Power Sources, 2015, 296, 204-214.

4 H. Takaba, T. Hisabe, T. Shimizu and M. K. Alam, J. Membr. Sci., 2017, 522, 237-244.

5 W. Lu, Z.-G. Shao, G. Zhang, Y. Zhao and B. Yi, J. Power Sources, 2014, 248, 905-914.

6 Q. Li, L. Liu, Q. Miao, B. Jin and R. Bai, Chem. Commun., 2014, 50, 2791-2793.

7 X. Qiu, M. Ueda, Y. Fang, S. Chen, Z. Hu, X. Zhang and L. Wang, Polym. Chem., 2016, 7, 5988-5995.

8 X. Gong, X. Yan, T. Li, X. Wu, W. Chen, S. Huang, Y. Wu, D. Zhen and G. He, J. Membr. Sci., 2017, 523, 216-224.

9 K. N. Grew and W. K. S. Chiu, J. Electrochem. Soc., 2010, 157, B327-B337.

10 J. Zhang, H. Liu, H. Liu, J. Hu, S. Tan and T. Wu, Polym. Bull., 2016, 74, 625-639.

11 J. Zheng, Q. Zhang, H. Qian, B. Xue, S. Li and S. Zhang, J. Membr. Sci., 2017, 522, 159-167.

12 X. Lin, Y. Liu, S. D. Poynton, A. L. Ong, J. R. Varcoe, L. Wu, Y. Li, X. Liang, Q. Li and T. Xu, J. Power Sources, 2013, 233, 259-268.
13 A. N. Lai, D. Guo, C. X. Lin, Q. G. Zhang, A. M. Zhu, M. L. Ye and Q. L. Liu, J. Power Sources, 2016, 327, 56-66.

14 M. I. Khan, C. Zheng, A. N. Mondal, M. M. Hossain, B. Wu, K. Emmanuel, L. Wu and T. Xu, Desalination, 2017, 402, 1018.

15 Y. Liu, B. Zhang, C. L. Kinsinger, Y. Yang, S. Seifert, Y. Yan, C. Mark Maupin, M. W. Liberatore and A. M. Herring, $J$. Membr. Sci., 2016, 506, 50-59.

16 J. Pan, C. Chen, L. Zhuang and J. Lu, Acc. Chem. Res., 2012, 45, 473-481.

17 J. Han, H. Peng, J. Pan, L. Wei, G. Li, C. Chen, L. Xiao, J. Lu and L. Zhuang, ACS Appl. Mater. Interfaces, 2013, 5, 1340513411.

18 C. Fujimoto, D.-S. Kim, M. Hibbs, D. Wrobleski and Y. S. Kim, J. Membr. Sci., 2012, 423, 438-449.

19 C. Yang, S. Wang, W. Ma, S. Zhao, Z. Xu and G. Sun, J. Mater. Chem. A, 2016, 4, 3886-3892.

20 D. Guo, Y. Z. Zhuo, A. N. Lai, Q. G. Zhang, A. M. Zhu and Q. L. Liu, J. Membr. Sci., 2016, 518, 295-304.

21 J. R. Varcoe and R. C. T. Slade, Fuel Cells, 2005, 5, 187-200. 22 B. Zhang, R. B. Kaspar, S. Gu, J. Wang, Z. Zhuang and Y. Yan, ChemSusChem, 2016, 9, 2374-2379.

23 C. T. Womble, G. W. Coates, K. Matyjaszewski and K. J. T. Noonan, ACS Macro Lett., 2016, 5, 253-257.

24 T. A. Sherazi, S. Zahoor, R. Raza, A. J. Shaikh, S. A. R. Naqvi, G. Abbas, Y. Khan and S. Li, Int. J. Hydrogen Energy, 2015, 40, 786-796.

25 C. Yang, S. Wang, W. Ma, L. Jiang and G. Sun, J. Mater. Chem. A, 2015, 3, 8559-8565.

26 R. Tsuchitani, H. Nakanishi, H. Shishitani, S. Yamaguchi, H. Tanaka and H. Kasai, Solid State Ionics, 2015, 278, 5-10.

27 K. M. Hugar, H. A. Kostalik and G. W. Coates, J. Am. Chem. Soc., 2015, 137, 8730-8737.

28 B. Lin, F. Chu, Y. Ren, B. Jia, N. Yuan, H. Shang, T. Feng, Y. Zhu and J. Ding, J. Power Sources, 2014, 266, 186-192.

29 O. M. M. Page, S. D. Poynton, S. Murphy, A. L. Ong, D. M. Hillman, C. A. Hancock, M. G. Hale, D. C. Apperley and J. R. Varcoe, RSC Adv., 2013, 3, 579-587.

30 H. Long and B. Pivovar, J. Phys. Chem. C, 2014, 118, 98809888.

31 H. Dong, F. Gu, M. Li, B. Lin, Z. Si, T. Hou, F. Yan, S.-T. Lee and Y. Li, ChemPhysChem, 2014, 15, 3006-3014.

32 R. Tsuchitani, H. Nakanishi and H. Kasai, e-J. Surf. Sci. Nanotechnol., 2013, 11, 138-141.

33 W. Wang, S. Wang, X. Xie, Y. Lv and V. Ramani, Int. J. Hydrogen Energy, 2014, 39, 14355-14361.

34 Y. Yang, J. Wang, J. Zheng, S. Li and S. Zhang, J. Membr. Sci., 2014, 467, 48-55.

35 Z. Si, L. Qiu, H. Dong, F. Gu, Y. Li and F. Yan, ACS Appl. Mater. Interfaces, 2014, 6, 4346-4355.

36 J. Hao, Y. Jiang, X. Gao, F. Xie, Z. Shao and B. Yi, J. Membr. Sci., 2017, 522, 23-30.

37 G. Mlostoń, J. Romański, M. Jasiński and H. Heimgartner, Tetrahedron: Asymmetry, 2009, 20, 1073-1080.

38 C. J. Serpell, N. L. Kilah, P. J. Costa, V. Felix and P. D. Beer, Angew. Chem., Int. Ed., 2010, 49, 5322-5326. 
39 J. Hao, X. Li, S. Yu, Y. Jiang, J. Luo, Z. Shao and B. Yi, J. Energy Chem., 2015, 24, 199-206.

40 J. Wang, S. Li and S. Zhang, Macromolecules, 2010, 43, 38903896.

41 Z. Zhang, K. Shen, L. Lin and J. Pang, J. Membr. Sci., 2016, 497, 318-327.

42 X. Gao, F. Lu, B. Dong, A. Wu, N. Sun and L. Zheng, J. Mater. Chem. A, 2016, 4, 13316-13323.

43 L. Gao, G. He, Y. Pan, B. Zhao, X. Xu, Y. Liu, R. Deng and X. Yan, J. Membr. Sci., 2016, 518, 159-167.

44 Y. Xu, J. Yang, N. Ye, M. Teng and R. He, Eur. Polym. J., 2015, 73, 116-126.
45 B. Wang, W. Sun, F. Bu, X. Li, H. Na and C. Zhao, Int. J. Hydrogen Energy, 2016, 41, 3102-3112.

46 F. Zhang, H. Zhang and C. Qu, J. Mater. Chem., 2011, 21, 12744-12752.

47 S. Pandit, S. Khilari, K. Bera, D. Pradhan and D. Das, Chem. Eng. J., 2014, 257, 138-147.

48 U. Thanganathan and M. Nogami, Int. J. Hydrogen Energy, 2014, 40, 1935-1944.

49 H. Zhang, B. Shi, R. Ding, H. Chen, J. Wang and J. Liu, Ind. Eng. Chem. Res., 2016, 55, 9064-9076.

50 W. Li, J. Fang, M. Lv, C. Chen, X. Chi, Y. Yang and Y. Zhang, J. Mater. Chem., 2011, 21, 11340-11346. 